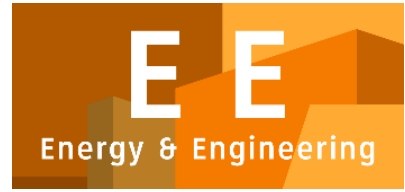

PAPER - OPEN ACCESS

\title{
Analisa Struktur Speed Bump Paduan Bahan Concrete Foam dan Polymeric Foam Dengan Variasi Rongga Menggunakan Sofware Ansys 14.5
}

$\begin{array}{ll}\text { Author } & : \text { Maragi Muttaqin } \\ \text { DOI } & : 10.32734 / \text { ee.v1i1.118 } \\ \text { ISSN } & : 2654-7031 \\ \text { E-ISSN } & : 2654-704 \mathrm{X}\end{array}$

Volume 1 Issue 1 - 2018 TALENTA Conference Series: Energy and Engineering

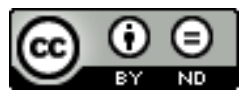

This work is licensed under a Creative Commons Attribution-NoDerivatives 4.0 International License.

Published under licence by TALENTA Publisher, Universitas Sumatera Utara
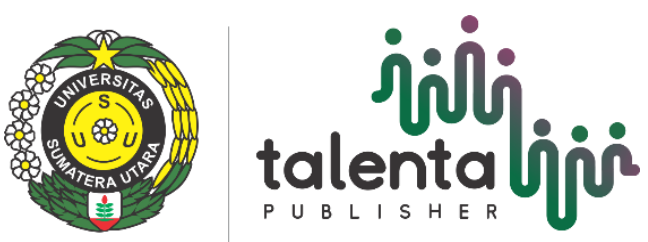


\title{
Analisa Struktur Speed Bump Paduan Bahan Concrete Foam dan Polymeric Foam Dengan Variasi Rongga Menggunakan Sofware Ansys 14.5
}

\author{
Abda $^{\mathrm{a}}$ \\ ${ }^{a}$ Fakultas Teknik, Universitas Sumatera Utara, Medan, 20155 \\ ${ }^{b}$ Fakultas MIPA, Universitas Sumatera Utara, Medan, 20155
}

Dino Hastrino $^{\mathrm{a}}$, Maraghi Muttaqin ${ }^{\mathrm{a}^{*}}$, Bustami Syam ${ }^{\mathrm{a}}$, Basuki WS ${ }^{\mathrm{b}}$, M. Sabri ${ }^{\mathrm{a}}$, dan S.

emjimuttaqin@ymail.com

\begin{abstract}
Abstrak
Speed bump adalah bagian jalan yang ditinggikan menggunakan tambahan aspal, karet, atau semen yang dipasang melintang di jalan untuk memperlambat laju/kecepatan kendaraan. Dalam riset ini, pertama sekali dijelaskan tentang desain serta pembuatan speed bump dengan geometri struktur padat dari bahan concrete foam yang diperkuat dengan serattan dan kosong kelapa sawit (TKKS). Speed bump dirancang dengan ukuran panjang $400 \mathrm{~mm}$, lebar $200 \mathrm{~mm}$ dan tinggi $150 \mathrm{~mm}$, memenuhi KM Menhub nomor 3 tahun 1994. Ada dua model speed bump, yaitu bentuk padat dan berongga. Selanjutnya kedua model dianalisis kekuatan strukturnya menggunakan program Ansys APDL 14.5. Pada model padat, jika gaya yang diberikan sebesar $80.000 \mathrm{~N}$ tegangan maximum yang terjadi pada bagian kritis struktur sebesar 8.01MPa. Dari hasil uji tekan diperoleh bahwa kekuatan tekan material confoam (type A5) adalah 2,1 MPa; sedangkan kekuatan tarik menggunakan Brazilian test sebesar 0,18 MPa. Bila dibandingkan dengan kekuatan tarik maksimum material confoam dapat disimpulkan bahwa struktur tidak aman untuk digunakan untuk beban maksimum (kenderaan truk), sesuai kelas jalan golongan IIIC.Untuk, itu perlu dilakukan redesign struktur speed bump. Struktur yang aman akan digunakan sebagai penggerak free-energy generator.
\end{abstract}

Kata Kunci: Speed bump; kekuatan struktur; ansys 14.5

\section{Pendahuluan}

Sudah banyak penelitian bahan bangunan yang dilakukan untuk mencari bahan bangunan yang kuat, ringan, tahan lama dan ekonomis. Dalam hal ini penggunaan beton dengan berat volume yang lebih ringan dari beton normal akan memberikan keuntungan yang signifikan antara lain: mengurangi luas penampang struktur, mereduksi beban gempa dan pondasi, dan mengurangi dampak lingkungan disekitar proyek. Berat volume beton dapat dikurangi dengan prinsip mengganti material bahan berbutir dengan rongga udara atau material pengisi yang lebih ringan. Tandan kosong kelapa sawit (TKKS) merupakan limbah yang dihasilkan pabrik pengolahan minyak kelapa sawit. Produksi Indonesia minyak kelapa sawit kasar indonesia mencapai 6 juta ton pertahun, dan secara bersaman dihasilkan pula limbah TKKS dengan potensi sekitar 2,5 juta ton per tahun (Anonim, 1999). Limbah ini biasanya dibakar sehingga dapat mencemari udara. Salah satu usaha dalam mengatasinya adalah dengan memanfaatkan tandan kosong kelapa sawit ini untuk pencampuran bahan concrete foam (confoam) yang dilakukan pencampurannya dengan metode 
fisika. Confoam dengan massa jenis yang lebih kecil digunakan untuk berbagai produk teknologi, misalnya sebagai bahan panel akustik, bata ringan, dll [2]. Dalam penelitian ini, bahan ini digunakan untuk speed bump (polisi tidur).

\section{Metode dan Bahan Penelitian}

Penelitian dimulai dengan survei keadaan speed bump yang telah terpasang di berbagai ruas jalan di Kota Medan. Ditemui bahwa masih banyak speed bump yang belum memenuhi standard KM Menhub nomor 3 tahun 1994. Untuk kebutuhan simulasi diperlukan beberapa parameter, antara lain: sifat mekanik dan fisik material confoam. Untuk itu material confoam disiapkan dan diuji untuk mendapatkan nilai modulus elastisitas (E), massa jenis $(\rho)$, kekuatan tarik $\left(S_{\mathrm{ut}}\right)$, dan kekuatan tekan $\left(\mathrm{S}_{\mathrm{uc}}\right)$. Penyelidikan distribusi tegangan pada speed bump dilaksanakan di IC-STAR USU. Adapun software yang digunakan adalah ANSYS Workbench 14.5 dengan basis metode elemen hingga. Langkah simulasi dengan menggunakan program ANSYS dapat dilakukan dalam 3 golongan proses pengerjaan yaitu: Preprocessing, solution, dan post processing. Data-data yang dimasukkan kedalam simulasi diambil dari datadata pengujian eksperimental. Alat dan bahan penelitian ditunjukkan pada Tabel 1 dan 2.

Tabel. 1. Alat

\begin{tabular}{clc}
\hline No & Nama Alat & Metode Fisika \\
\hline 1 & $\begin{array}{l}\text { Alat uji tekan statik beton menggunakan mesin } \\
\text { Compression Testing Machine buatan Jerman dengan } \\
\text { standar ASTM C-39 dan maksimum kompresi hingga }\end{array}$ & $\checkmark$ \\
& 10.000 Psi & \\
2 & Horizontal shaft mixer & $\checkmark$ \\
3 & Kompressor & $\checkmark$ \\
4 & Foam generator & $\checkmark$ \\
5 & Timbangan digital & $\checkmark$ \\
6 & Mesin penghalus serat & $\checkmark$ \\
7 & Software Auto CAD \& ANSYS & $\checkmark$ \\
8 & Cetakan & $\checkmark$ \\
9 & Gelas ukur & $\checkmark$ \\
\hline
\end{tabular}

Tabel. 2. Bahan

\begin{tabular}{clc}
\hline No & Nama Bahan & Metode Fisika \\
\hline 1 & Pasir & $\checkmark$ \\
2 & Semen & $\checkmark$ \\
3 & Air bersih & $\checkmark$ \\
4 & Deltamix blowing agent & $\checkmark$ \\
5 & Serat TKKS & $\checkmark$ \\
\hline
\end{tabular}

Persiapan serat TKKS diperoleh dari hasil pengolahan tandan kosong kelapa sawit dengan beberapa tahapan proses. Tahapan tersebut adalah:

- Perendaman TKKS dalam air yang mengandung larutan $\mathrm{NaOH} 1 \%$ selama 24 jam.

- Pencucian dengan air bersih.

- Pengeringan dengan cara menjemur serat ini pada sinar matahari selama \pm 3 hari atau dapat juga menggunakan mesin pengering.

- Pencacahan serat menjadi bagian-bagian kecil (5 s.d. $10 \mathrm{~cm})$.

- Penghalusan serat dengan menggunakan mesin penghalus serat 
Proses pembuatan concrete foam dengan metode fisika adalah sebagai berikut :

- Mengayak pasir; untuk mendapatkan ukuran butir yang sama dan memisahkan partikel lain yang tidak dibutuhkan seperti kotoran-kotoran kayu, daun kering, dll.

- Mengayak semen; untuk memisahkan gumpalan-gumpalan semen yang disebabkan oleh kelembaban lingkungan penyimpanan.

- Persiapkan serat TKKS; timbang serat ini sesuai dengan komposisi yang telah ditentukan. Pemilihan serat berbentuk serat panjang antara $0,5-1 \mathrm{~cm}$.

- Hidupkan horizontal shaft mixer

- Masukkan pasir + semen + air ke dalam horizontal shaft mixer sampai pasir, air dan semen tercampur secara merata

- Hidupkan mesin foam generator; gunakan blowing agent dari bahan deltamix foam agent sampai busa terbentuk danpisahkan.

- Campurkan urutan e + serat TKKS; aduk kembali campuran ini dengan menggunakan horizontal shaft mixer sampai merata.

- Masukkan foam/busa yang dibangkitkan oleh foam generator ke dalam campuran pada urutan 7 .

- Setelah pengadukan beberapa menit kemudian, maka hasil akhir adalah foam mortar atau beton berbusa dengan agregat ringan serat TKKS, dan segera mengecor atau menuangkan ke dalam cetakan yang telah disiapkan terlebih dahulu.

\section{Hasil dan Pembahasan}

\subsection{Geometri, dimensi, dan material spped bump}

Desain yang dilakukan adalah berupa struktur yang terdiri dari dua potongan, yaitu A dan B, di mana potongan A berbentuk segi empat dan potongan B berbentuk parabola. Dimensi kedua bentuk speed bump secara detil ditunjukkan pada Gbr. 1, di mana lebarnya $200 \mathrm{~mm}$ dan tinggi dari permukaan jalan $50 \mathrm{~mm}$, panjang speed bump menyesuaikan dengan lebar jalan; dalam simulasi ukuran panjang speed bump dibuat dengan ukuran $400 \mathrm{~mm}$. Geometri dan dimensi speed bump dapat diubah andai kata tidak memenuhi standard kekuatan struktur.

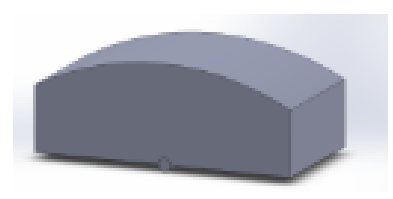

(a) 1 inchi

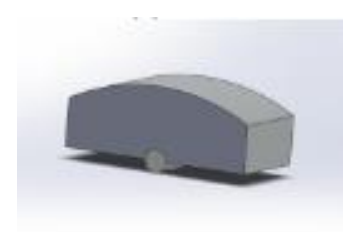

(b) 2 inchi

Gambar. 1. Geometri dan dimensi desain speed bump berongga (a) 1 inchi (b) 2 inchi
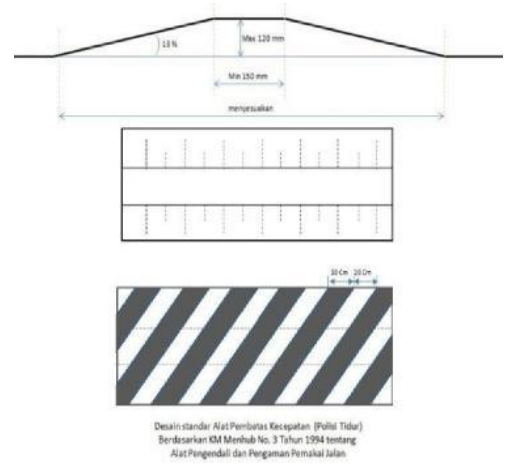
Gambar. 2. Peraturan Kemenhub nomor 31994

Ukuran yang digunakan serta geometri adalah modifikasi dari Peraturan Kemenhub no 3 tahun 1994 (Gbr. 2). Pada penelitian ini, material speed bump dibuat dari bahan concrete foam, baik untuk geometri Gambar 1 (a) dan (b). Dari hasil pengujian sifat mekanik material yang diperlukan dalam simulasi diperoleh dan dapat ditunjukkan dalam Tabel 3.

Tabel. 3. Sifat mekanik material speed bump ( Laporan penelitian MP3EI )

\begin{tabular}{ccccc}
\hline Type spesimen & $\mathrm{S}_{\mathrm{uc}}(\mathrm{MPa})$ & $\mathrm{S}_{\mathrm{ut}},(\mathrm{MPa})$ & $\rho$ & $\mathrm{E}(\mathrm{MPa}$ \\
\hline A5 & 2.1 & 0.18 & 0.2 & 10.1
\end{tabular}

\subsection{Simulasi uji tekan static pada desain speed bump}

Dalam penelitian ini, struktur speed bump disimulasi dengan pembebanan statik, dengan asumsi bahwa kenderaan melewati speed bump dengan kecepatan rendah. Hasil uji tekan statik yang diperoleh dari simulasi menggunakan program Ansys 14.5 APDL adalah berupa respon dari struktur speed bump dalam bentuk tegangan. Hasil simulasi Ansys 14.5 untuk speed bump berongga, ditunjukkan pada Gambar a,b,c masing-masing untuk distrubusi tegangan sumbu $\mathrm{X}$, sumbu Y dan tegangan prinsipal.

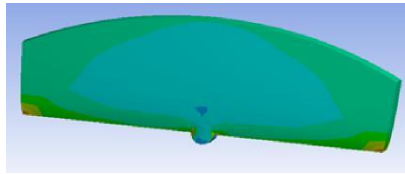

(a) Tegangan arah $\mathrm{X}(\mathrm{MPa})$

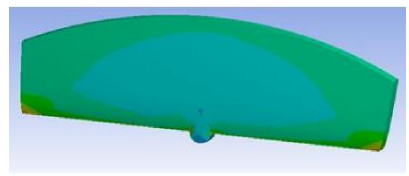

(b) Arah sumbu Y (MPa)

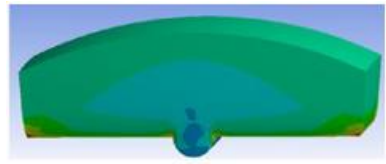

(e) Tegangan pada sumbu Y

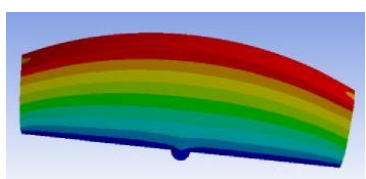

(c) Tegangan prinsipal

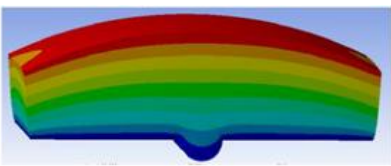

(f) Tegangan prinsipal

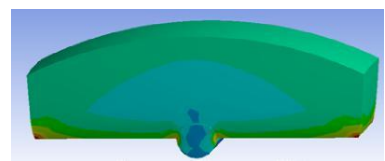

(d) Tegangan arah sumbu X

Gambar. 3. Simulasi uji tekan static

Hasil simulasi Ansys 14.5 untuk speed bump padat, ditunjukkan pada Gbr. d-e, masing-masing untuk distrubusi tegangan sumbu X, sumbu Y dan tegangan prinsipal.

Dari gambar terlihat bahwa distribusi tegangan pada pemodelan speed bump tidak merata, di mana terjadi konsentrasi tegangan arah $\mathrm{x}(\square \mathrm{x})$ pada bagian tengah penampang; sedangkan pada penampang berongga konsentrasi tegangan tarik arah $\mathrm{x}, \square \mathrm{x}$ terjadi pada bagian di atas rongga. Bentuk keretakan dapat diprediksikan dengan melihat kontur tegangan prinsipal.

Sebagaimana ditunjukkan pada hasil simulasi di atas bahwa distribusi tegangan tarik yang terjadi sebesar 77.6 MPa. Dari hasil uji tekan diperoleh bahwa kekuatan tekan material confoam (type A5) adalah 2,1 MPa; sedangkan kekuatan tarik menggunakan Brazilian test sebesar 0,18 MPa. Bila dibandingkan dengan kekuatan tarik maksimum material confoam dapat disimpulkan bahwa struktur tidak aman untuk digunakan pada beban maksimum (kenderaan truk), sesuai kelas jalan golongan IIIC. Perbandingan hasil simulasi model berongga dan padat di tunjukkan pada Tabel 4.

Tabel. 4. Perbandingan hasil struktur berongga dan padat

\begin{tabular}{cccc}
\hline & $(\square \mathrm{x})$ & $(\square \mathrm{y})$ & $(\square 1)$ \\
\hline Berongga & 77.6 & 63.5 & 77.5 \\
\hline Padat & 8.01 & 8.04 & 8.36 \\
\hline
\end{tabular}




\section{Kesimpulan}

Berdasarkan penelitian dan analisis yang telah dilakukan maka kesimpulan dari hasil penelitian ini yaitu :

- Telah dilakukan desain speed bump dengan geometri struktur berongga dan padat dari concrete foam (confoam) yang diperkuat dengan serattan dan kosong kelapa sawit, memiliki dimensi panjang $400 \mathrm{~mm}$, lebar $200 \mathrm{~mm}$ dan tinggi $150 \mathrm{~mm}$.

- Dari hasil simulasi static menggunakan program Ansys APDL 14.5,dengan gaya yang diberikan sebesar $80.000 \mathrm{~N}$ diperoleh tegangan maximumnya adalah 8.01 N. Dari hasil uji tekan diperoleh bahwa kekuatan tekan material confoam (type A5) adalah 2,1 N; sedangkan kekuatan tarik menggunakan Brazilian test sebesar 0,18 $\mathrm{N}$. Bila dibandingkan dengan kekuatan tarik maksimum material confoam dapat disimpulkan bahwa struktur tidak aman untuk digunakan untuk beban maksimum (kenderaan truk), sesuai kelas jalan golongan IIIC primer; dapat digunakan untuk golongan jalan IIIC sekunder dimana beban maksimum mencapai 2 ton. Dari kedua model speed bump, model dengan penampang padat yang dapat disarankan untuk diproduksi.

- Untuk itu, perlu dilakukan redesign struktur speed bump. Struktur yang aman akan digunakan sebagai penggerak awal free-energy generator.

\section{Referensi}

[1] http://id.wikipedia.org/wiki/Polisi tidur

[2] Syam, B., Samsul R, Basuki WD, dan Zulfikar, Laporan Riset MP3EI 2013.

[3] Zulfadhli dan B. Syam, Pengembangan Model dan Analisa Respon Parking Bumper dari Bahan Polymeric Foam Diperkuat Serat Tandan Kosong Kelapa Sawit (TKKS) terhadap Beban Impak Jatuh Bebas, Jurnal e-Dinamis, Volume. 6, No.2 September 2013, pp. 108-116.

[4] Irwan, A, Mahadi, R.D.W. Lubis, dan B. Syam, Pengembangan Material Komposit Busa Polimer Menggunakan Serat TKKS Sebagai Penguat, Prosiding Seminar Nasional Rekayasa dan Teknologi (SNRT), 4 Des. 2013, Reuleut Lhokseumawe, pp. $367-371$.

[5] Kaban, N.L dan B. Syam, Pengaruh Pembebanan Impak Jatuh Bebas pada Concrete Foam dengan Variasi Komposisi Poliuretan yang Diperkuat Serat TKKS, Jurnal e-Dinamis, Volume. 10, No.2 September 2014, pp. 135-142.

[6] Maraghi, M., N. Fitriadi, Y. Siahaan, Abdurrahman, Irwansyah, dan B. Syam, Pembuatan dan Analisis Struktur Speed Bump Bahan Komposit Busa Beton (Concrete Foam), Prosiding Seminar Nasional Rekayasa dan Teknologi (SNRT), 4 Des. 2013, Reuleut Lhokseumawe, pp. 343-351. 